\title{
Study of TH1/TH2 Cytokine Profiles in HIV/AIDS Patients in a Tertiary Care Hospital in India
}

Ravinder Kaur ${ }^{1 *}$, Megh Singh Dhakad', Ritu Goyal', Preena Bhalla ${ }^{1}$ and Richa Dewan ${ }^{2}$

${ }^{1}$ Department of Microbiology, Maulana Azad Medical College and Associated Lok Nayak Hospitals, New Delhi-110002, India

${ }^{2}$ Department of Medicine, Maulana Azad Medical College and Associated Lok Nayak Hospitals, New Delhi-110002, India

\begin{abstract}
Background and Objectives: Switch of cytokines from a T helper 1 (Th1) to a Th2 is an important factor in the progression of HIV infection to AIDS. Hence, our objectives were to analyze the levels of Th1 (IL-2, IFN- $\gamma$ ) and Th2 (IL-4, IL-10) cytokines and their correlation with clinical and immunological profiles in HIVIAIDS patients.

Methods: We studied 234 symptomatic HIV positive patients (case group) attending OPDs, ART clinic and medical wards of the Hospital. CD4+T-cell count was determined by flow cytometry using Fluorescent Activated Cell Sorter Count system. Quantitative determination of cytokines (Th1 subtype: IL-2, IFN-y and Th2 subtype: IL-4, IL-10) was done by ELISA.

Results: Patients (08-68 years) had CD4+T-cell counts ranged from $16-1033$ cells/ $\mu$ l. The median CD4+T cell count was 204.50 cells/ $\mu \mathrm{l}$ and the mean was 265.48 cells/ $\mu$ l. The concentration of IL-2 and IFN- $\gamma$ were significantly lower in case group compared to asymptomatic HIV patients $(P<0.001)$ while the IL-4 in symptomatic HIV negative was higher than healthy controls and case group compared to asymptomatic HIV patients. Concentration of IL-10 was also higher in case group compared to asymptomatic HIV patients. A positive correlation was found between IL-4, IFN-y, IL-2 with CD4+T-cells and a negative correlation between IL-10 and CD4+T-cells among the case group.

Conclusions: Hence a decline in type-1 cytokines (IFN-y, IL-2) and rise in type-2 cytokines (IL-4, IL-10) was observed in symptomatic patients with HIV infection in comparison to asymptomatic HIV patients suggesting a shift from Th1 to Th2 type cytokine response.
\end{abstract}

Keywords: AIDS; CD4+T-cell count; CDytokines; HIV; Interleukins

\section{Introduction}

The clinical profile of AIDS in India seems to be different from rest of the world, since in India the HIV infected patients lives with locally prevalent infectious diseases. Among the various immunological parameters assessed about their applicability as predictors of HIV disease progression, CD4+T-cell counts have been found to be the most reliable [1]. HIV infection lead to a progressive loss of CD4+Tcells and eventually to the onset of AIDS [2], HIV/AIDS is a global health problem [3].

The roles of cytokines in the progression of HIV-associated disease are controversial. The patterns of innate cytokine production have been postulated to shift in the course of HIV infection. This shift has been described as a change from an environment characterized predominantly by Th1 cytokines, associated with cell-mediated immune responses, to an environment in which Th2 cytokines, known to enhance humoral immune responses, are more prevalent [4].

The T cell defects involve virtually every limb of the immune system, indicating the critical dependence of the integrity of the immune system on the inducer/helper function of CD4+T-cells. Essentially every $\mathrm{T}$ cell function has been reported to be abnormal at some stage of HIV infection. These abnormalities include defective T-cell cloning and colony-forming efficiencies, impaired expression of IL-2 receptors, defective IL- 2 production, and decreased IFN- $\gamma$ production in response to antigens [5].

Recently, considerable emphasis has been laid on the role of cytokines in regulation of immunopathogenesis in HIV infection [6]. The T helper (Th) cells have been characterized into two subgroups i.e. Th1 and Th2 with differing pattern of cytokine profiles [7]. Th1 pattern of cytokines are characterized by secretion of IL-2, IL-12 and IFN- $\gamma$. These cytokines are associated with a protective response. On the other hand, the Th2 specific cytokines i.e. IL-4, IL-5, IL-6, IL-10 and IL-13 [8] are associated with disease progression and lead to the progression of HIV infection to AIDS [9]. A shift from a Th1 to a Th2 cytokine pattern has been previously hypothesized to parallel or even precede the progressive CD4 impairment that accompanies the transition towards the final stage of acquired immunodeficiency syndrome (AIDS) [10]. To date some groups have shown evidence for supporting the Th1 $\rightarrow$ Th2 hypothesis, while others have shown the opposite [9]

Although there have been studies of cytokines in HIV/AIDS patients, there are scant data available from India on clinical, immunological and cytokine profile of HIV/AIDS patients. Hence the main objectives of this study were to evaluate the cytokine levels and their correlation with clinical and immunological profiles to assess the immunodeficiency in HIV/AIDS patients.

\section{Materials and Methods}

\section{Study population and data collection}

Present study was conducted at the Department of Microbiology, Maulana Azad Medical College, New Delhi. Symptomatic HIV positive

*Corresponding author: Ravinder Kaur, Department of Microbiology, Lady Hardinge Medical College and Associated Hospitals, New Delhi-110001, India, Tel: 01123408185; E-mail: rkaur@gmail.com

Received November 30, 2015; Accepted January 07, 2016; Published January 11, 2016

Citation: Kaur R, Dhakad MS, Goyal R, Bhalla P, Dewan R (2016) Study of TH1/ TH2 Cytokine Profiles in HIVIAIDS Patients in a Tertiary Care Hospital in India. Med Microb Diagn 5: 214. doi:10.4172/2161-0703.1000214

Copyright: (c) 2016 Kaur R, et al. This is an open-access article distributed under the terms of the Creative Commons Attribution License, which permits unrestricted use, distribution, and reproduction in any medium, provided the original author and source are credited. 
patients $(n=234)$ of all age groups and both sexes attending outpatient department (OPDs) or Anti-retroviral treatment clinic (ART clinic) or admitted in the medical wards of L.N.J.P and G.B. Pant Hospital were taken as subjects. All patients were evaluated by a pre designed protocol covering the biodata, history including mode of transmission, presenting complaints and physical examination.

\section{Ethics approval}

This study was approved by the institutional ethics committee of Maulana Azad Medical College and Associated Hospitals (Lok Nayak, GB Pant Hospital, Guru Nanak Eye Centre, and Chacha Nehru Bal Chikitsalaya) New Delhi-110002, India. Informed consent was obtained from all patients or their parents or guardians.

\section{Study groups}

Case group: $234 \mathrm{HIV}$ positive patients with clinical complaints and positive for anti-HIV-1/2 antibodies.

Symptomatic HIV negative: $50 \mathrm{HIV}$ negative patients with clinical complaints and negative for anti-HIV-1/2 antibodies.

Asymptomatic HIV positive: $50 \mathrm{HIV}$ positive patients without clinical complaints and positive for anti-HIV-1/2 antibodies. None of them showed any sign of the disease.

Healthy control: 50 healthy controls with no clinical complaints and negative for anti-HIV-1/2 antibodies. None of them showed any sign of the disease.

Evaluation of immunodeficiency: Evaluation of immunodeficiency in HIV/AIDS patients was done by CD4+T-cell count and by estimation of Cytokines (Th1 subtype: IL-2, IFN- $\gamma$ and Th2 subtype: IL-4, IL-10) levels in serum of the patients. Peripheral venous blood sample was obtained by aseptic venipuncture in EDTA treated tubes. An aliquot of whole blood was used for the enumeration of CD4+T-cells. The anticoagulated whole blood was stored at $18-25^{\circ} \mathrm{C}$ and processed within six hours. From the remaining blood, serum was separated immediately in order to avoid the decay of cytokines. Blood separated serum samples were kept in sterile non siliconized tubes and were stored in deep freezers at $-70^{\circ} \mathrm{C}$ until the cytokine levels were measured.

CD4+T-cell counts: The anticoagulated whole blood sample was incubated with the fluorescent antibodies. Processed sample was then analyzed and CD4+T-cell count was determined by flow cytometry using Fluorescent Activated Cell Sorter BD FACSCount ${ }^{\mathrm{TM}}$ system (Becton Dickinson) as per manufacturer's instructions.

Measurement of plasma cytokines: Quantitative determination of cytokines (Th1 subtype: IL-2, IFN- $\gamma$ and Th2 subtype: IL-4, IL-10) was done by ELISA in serum utilizing the standard enzyme immunoassay kits according to manufacturer instructions. Serum samples were thawed in a $37^{\circ} \mathrm{C}$ water bath and diluted with sample diluents, while standards were reconstituted in standard diluents. Eight standards were made in duplicate by serial dilution. Standards and samples were incubated in a multi-well plate for 2.5 hours. Following this, detection antibody was added to each standard and sample, and a further 1 hour incubation period was observed. Streptavidin-HRP was used as the fluorochrome for antibody detection and incubated for 45 minutes. TMB one-step substrate reagent was added and incubated for 30 minutes in the dark. All the incubations were done at room temperature with gentle shaking. Finally stop solution was added and reading was taken at $450 \mathrm{~nm}$ immediately.

\section{Statistical analysis}

Median cytokine expression levels of case group were compared to controls. The generalized linear model (GLM) was applied to compute the relation between CD4+T-cell count level and IL-2, IFN- $\gamma$, IL-10, IL-4 and TLC (total leucocytes count) respectively, estimated regression coefficients values were calculated $(\mathrm{P}<0.05$ is considered as significant level). All statistical analyses were done with the Statistical Package for the Social Sciences (version 17.0; SPSS S.L., Madrid, Spain). All tests of statistical significance were two tailed.

\section{Results}

Although there was no special age distribution, patients belonged to a wide age group from 08 to 68 years. Maximum number of cases belonged to $21-40$ years (75.64\%), the most productive age group of the country. We found that males were more commonly infected, and a male predominance was seen in most age groups. Sociodemographic profiles of different group of patients are shown in Table 1.

Subjects were divided into three subgroups based on CD4+T-cell counts at the time of the selected visit: $<200,200$ to 499 , and $>500$ cells/ $\mu \mathrm{l}$. Most of the patients in case group (47.44\%) had CD4+T-cell count

\begin{tabular}{|c|c|c|c|c|c|}
\hline Characteristics & Variable & $\begin{array}{l}\text { Healthy control } \\
(\mathrm{N}=50)\end{array}$ & $\begin{array}{l}\text { Asymptomatic HIV Positive } \\
\qquad(\mathrm{N}=50)\end{array}$ & $\begin{array}{c}\text { Symptomatic HIV Negative } \\
(\mathrm{N}=50)\end{array}$ & $\begin{array}{l}\text { Symptomatic HIV } \\
\text { positive }(\mathrm{N}=234)\end{array}$ \\
\hline Age in years & Mean age & 34.28 & 34.50 & 33.47 & 34.09 \\
\hline \multirow{3}{*}{ Sex } & Male & 34 & 35 & 30 & 158 \\
\hline & Female & 16 & 15 & 20 & 70 \\
\hline & Transgender & 0 & 0 & 0 & 06 \\
\hline \multirow{2}{*}{ Marital Status } & Married & 39 & 40 & 39 & 192 \\
\hline & Not Married & 11 & 10 & 11 & 42 \\
\hline \multirow{3}{*}{ HIV status of partner } & HIV Positive & NA & 18 & NA & 109 \\
\hline & HIV Negative & NA & 12 & NA & 40 \\
\hline & Unknown & NA & 04 & NA & 43 \\
\hline \multirow[t]{2}{*}{ Residence } & Urban & 46 & 43 & 45 & 193 \\
\hline & Rural & 4 & 7 & 5 & 41 \\
\hline \multirow{3}{*}{ CD4+T-cell count (cells/ul) } & $<200$ (cells/ul) & 0 & 02 & 0 & 107 \\
\hline & 200-499 (cells/ul) & 0 & 09 & 03 & 111 \\
\hline & $>500($ cells/ul $)$ & 50 & 39 & 47 & 16 \\
\hline $\begin{array}{l}\text { Total lymphocyte count (cells/ } \\
\mathrm{mm}^{3} \text { ) }\end{array}$ & Mean & 6944.2 & 7857.4 & 9305.3 & 7239.7 \\
\hline
\end{tabular}

Table 1: Sociodemographic profile in different group of patients. 
200-499 while in case of healthy control (50/50), asymptomatic HIV Positive (39/50) and symptomatic HIV Negative (47/50) patients group had $>500 \mathrm{CD} 4+\mathrm{T}$-cell count. Majority of the patients in case group (93.16\%) had of CD4+T-cell count ranging from $0-500$ while only $(06.84 \%)$ had a count of $>500$. Mean CD4+T-cell count in Case group was much lower (219.52) compared to control group of asymptomatic HIV positive patients (624.03).

In the case of cytokine Th1 subtypes; the IL-2 concentrations were higher in symptomatic HIV negative patients compared to healthy controls, but the difference was not statistically significant while IL-2 levels in the case group were significantly lower than asymptomatic HIV positive patients $(\mathrm{P}<0.001)$. IFN- $\gamma$ levels also seemed to be

\begin{tabular}{|c|c|c|c|c|}
\hline \multirow{3}{*}{ Subjects } & \multicolumn{2}{|c|}{ TH1 subtypes } & \multicolumn{2}{|c|}{ TH2 subtypes } \\
\hline & IL-2 (pg/ml) & $\begin{array}{l}\text { IFN-Y (pg/ } \\
\mathrm{ml})\end{array}$ & IL-4 (pg/ml) & $\begin{array}{l}\text { IL-10 (pg/ } \\
\mathrm{mI})\end{array}$ \\
\hline & Mean \pm S.D & Mean \pm S.D & Mean \pm S.D & Mean \pm S.D \\
\hline Healthy control $(\mathrm{N}=50)$ & $6.30 \pm 1.89$ & $7.31 \pm 2.44$ & $5.60 \pm 1.31$ & $6.80 \pm 2.18$ \\
\hline $\begin{array}{l}\text { Asymptomatic HIV } \\
\text { Positive }(\mathrm{N}=50)\end{array}$ & $789 \pm 560.6$ & $\begin{array}{c}1942.5 \pm \\
1113.2\end{array}$ & $10.6 \pm 35.18$ & $12.5 \pm 7.7$ \\
\hline $\begin{array}{l}\text { Symptomatic HIV } \\
\text { Negative }(\mathrm{N}=50)\end{array}$ & $32.6 \pm 109.5$ & $\begin{array}{c}132.7 \pm \\
295.9\end{array}$ & $14.2 \pm 43.7$ & $11.6 \pm 29.9$ \\
\hline $\begin{array}{l}\text { Symptomatic HIV } \\
\text { positive }(\mathrm{N}=234)\end{array}$ & $\begin{array}{c}125.92 \pm \\
103.34\end{array}$ & $\begin{array}{c}455.59 \pm \\
797.59\end{array}$ & $6.57 \pm 18.24$ & $\begin{array}{c}30.67 \pm \\
53.80\end{array}$ \\
\hline
\end{tabular}

Table 2: Cytokine profiles in different group of patients. significantly lower in the case group compared to asymptomatic HIV positive patients $(\mathrm{P}<0.001)$ (Table 2$)$.

In the case of cytokine Th2 subtypes; the IL- 4 concentrations in symptomatic HIV negative individuals were higher than healthy controls and case group compared to asymptomatic HIV positive patients but the difference was not statistically significant. IL-10 levels were higher in symptomatic HIV negative patients compared to healthy controls and also higher in case group compared to asymptomatic HIV positive patients but the difference was not statistically significant (Table 2). Figure 1 showed the concentrations of different cytokines (IL-2, IFN- $\gamma$, IL-4, IL-10) and CD4+ T cell count and total lymphocyte count (TLC) in different group of patients.

Subsequently, the estimated regression coefficient values were obtained between CD4+T-cells, cytokine levels and TLC respectively.

In case group in comparison to symptomatic HIV negative patients, the linear relation between CD4+T-cell and IL-2, IFN- $\gamma$, IL-10, IL- 4 and TLC respectively shows that the regression coefficients for IL-2, IFN $-\gamma$, IL-10, IL- 4 and TLC are $0.05,0.00,-0.03,0.99$ and -0.001 respectively. It shows non-significant relation between biochemical parameters and $\mathrm{CD} 4+\mathrm{T}$-cell. One to one relation between $\mathrm{CD} 4+\mathrm{T}$-cell and covariates with IL-2(0.04), IFN- $\gamma$ (0.00) and IL-4(0.96) respectively, shows positive relations between CD4+T-cell and IL-4 with 0.96 , however the relation was not significantly observed and the relation between

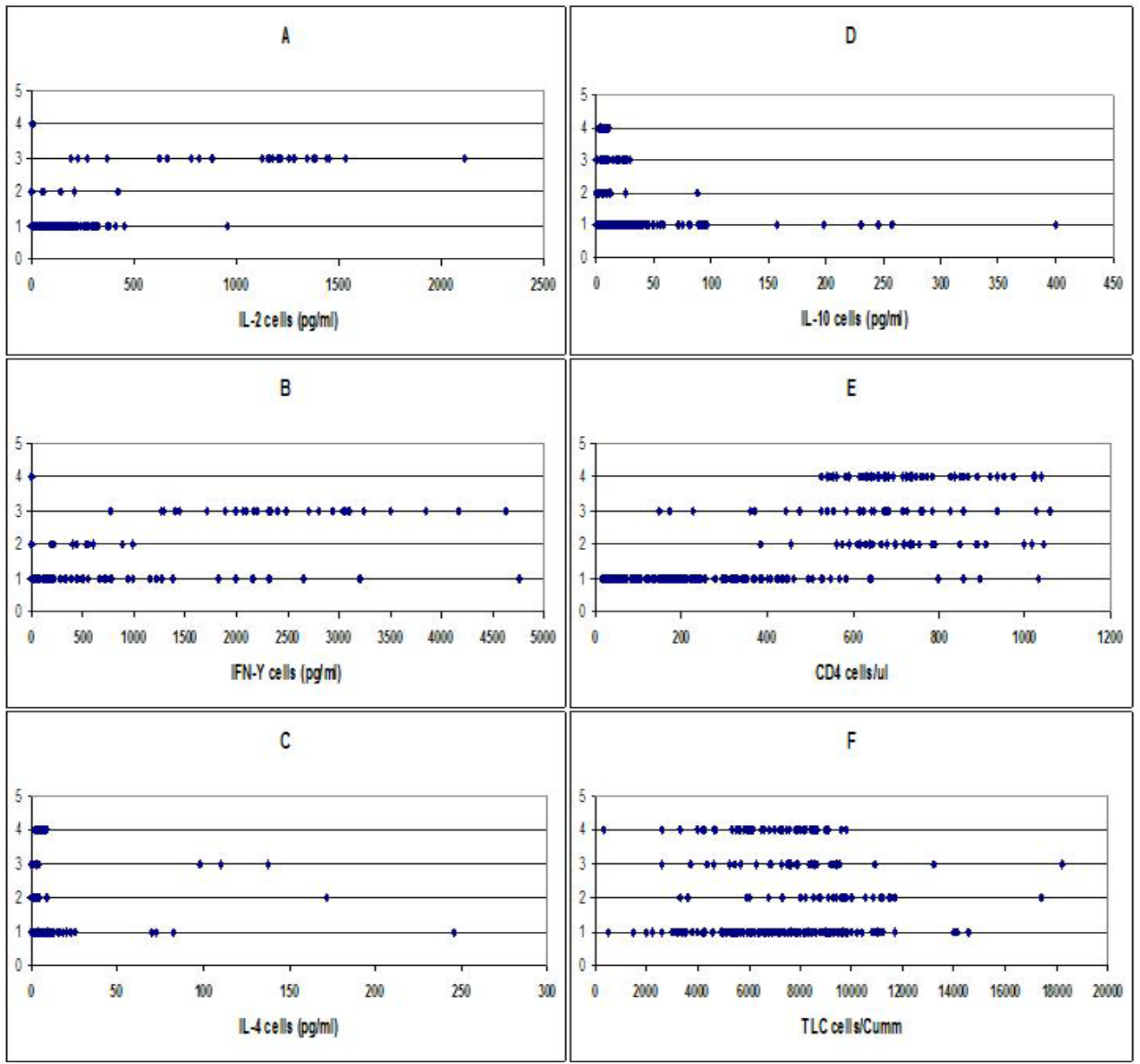

Figure 1: A; IL 2 levels, B; IFN-Y levels, C; IL 4 levels, D; IL 10 levels, E; CD4+T cell count, F; TLC levels in different group of patients. In figure A to F at Y axis 1 is case group, 2 is symptomatic HIV negative patients, 3 is asymptomatic HIV positive patients, 4 is healthy controls 
CD4+T-cell and covariates with IL-10(-0.06) and TLC(-0.00), and shows the negative relations.

In case group in comparison to asymptomatic HIV positive patients, the linear relation between CD4+T-cell and IL-2, IFN- $\gamma$, IL10 , IL- 4 and TLC respectively shows that the regression coefficients for IL-2, IFN- $\gamma$, IL-10, IL- 4 and TLC are $0.02,0.04,-0.05,0.53$ and 0.00 respectively. It shows non-significant relation between biochemical parameters and CD4+T-cell. The one to one relation between CD4+Tcell and covariates with IL-2 (0.32) and IFN- $\gamma(0.04)$, shows positive significant relations. While the relation between $\mathrm{CD} 4+\mathrm{T}$-cell and covariates with IL-4(1.03) and TLC (0.00), shows positive relations between CD4+T-cell and IL-4 with 1.03, however the relation was not significantly observed. However, the relation between CD4+T-cell and covariate with IL-10(-0.26) shows the negative non-significant relations.

In symptomatic HIV negative patients and asymptomatic HIV positive patients, the linear relation between CD4+T-cell and IL2 , IFN- $\gamma$, IL-10, IL- 4 and TLC respectively shows the regression coefficient for IL-2, IFN- $\gamma$, IL-10, IL-4 and TLC are 0.05, 0.03, 9.78, -1.72 and 0.03 respectively. It shows non-significant relation between biochemical parameters and CD4+T-cell. On checking the one to one relation between biochemical parameters and CD4+T-cell, no significant relations are present. The relation between CD4+T-cell and covariates with IL-2 (0.01), IFN- $\gamma(0.03)$, IL-10(8.26) and TLC (0.00) respectively shows positive non-significant relations. While the relation between CD4+T-cell and covariates with IL-4(-0.59) shows negative non-significant relations.

\section{Discussion}

Different study groups (four) of patients were recruited into this study: Case group (symptomatic HIV positive), asymptomatic HIV positive, symptomatic HIV negative and healthy controls. Demographic profiles of different group of patients are summarized in Table 1.

The CD4+T-cell count is the laboratory test generally accepted as the best marker of the immediate state of immunological competency of the patient with HIV infection [11]. Among the HIV patients, mean CD4+T-cell count in the case group was much lower (219.52) compared to asymptomatic HIV patients (624.03) quite consistent to a study, where the mean CD4+T-cell counts and percentages to be lower in HIV infected individuals compared to controls [12]. A low CD4+T-cell count exposes the HIV patients to an increased risk of opportunistic infections.

Although, HIV is the etiological agent of AIDS in humans. The infection is usually accompanied by changes in the synthesis and secretion of several immunologically important cytokines [13]. These cytokine disturbances play significant role in progression of HIV infection to AIDS [9].

In our study, cytokine concentrations of Th1 subtypes (IL-2 and IFN- $\gamma$ ) were highest in asymptomatic HIV positive >case group $>$ symptomatic HIV negative > healthy controls. The IL-2 levels in the case group were significantly lower than asymptomatic HIV positive patients $(\mathrm{P}<0.001)$. The plasma levels of IL-2 have been reported to be markedly decreased in HIV infected participants [14]. Elevated IL-2 serum levels were detected in asymptomatic patients naive of antiretroviral treatment and with a more stable immune state. This finding indicates a predominance of type- 1 cytokine and may reflect a cellular immune effect or response in the early stages [15].

Another Th1 subset cytokine essential for eliminating intracellular pathogens, IFN- $\gamma$, has been to be decreased with HIV infection [14], and our results confirmed these assumptions, IFN- $\gamma$ levels were seen to be significantly lower in case group compared to asymptomatic HIV positive patients $(\mathrm{P}<0.001)$. Chronic HIV infection features depletion of Th cells that normally secrete IFN- $\gamma$ (a sign of Th1 activity) [16] The mean IFN- $\gamma$ level was lower among controls in comparison to asymptomatic HIV infected individuals, but this difference was not significant. Significantly higher IFN- $\gamma$ levels were found among the symptomatic $(\mathrm{P}<0.05)$ and AIDS groups $(\mathrm{P}<0.001)$ compared to asymptomatic groups as reported by Ramalingam et al. [12]. It was thought that the increase in plasma IFN $-\gamma$ seen here could represent the IFN- $\gamma$ produced by the CD8 $\mathrm{T}$ cells, a large proportion of T cells and the increase in IFN- $\gamma$ levels in their study was thought to be probably because of the increase in the percentage of CD8 T cells [12].

Cytokine concentrations of Th2 subtypes: IL- 4 was highest in symptomatic HIV negative > asymptomatic HIV positive > case group $>$ healthy controls, while IL-10 highest in case group $>$ asymptomatic HIV positive $>$ symptomatic HIV negative $>$ healthy controls. Soufian et al. [9], showed low serum levels of IL-4 in HIV infected individuals compared with HIV negative subjects [9]. Concerning IL-4, there was a peak of cytokine expression per cell in HIV-infected individuals without AIDS compared with both the patients with AIDS and the healthy controls [8].

However, another Th2 subset, IL-10 levels were higher in case group compared to asymptomatic HIV positive patients. Specifically, IL-10, an immunosuppressive cytokine with roles in inhibiting the Th1 response was seen to be increased in patients with HIV infection. The plasma levels of this cytokine in HIV subjects showed a significant increase as reported by Tudela et al in their study in 2014 [14]. The level of IL-10 expression per cell was seen to be highest in CD4+T-cells from patients with AIDS [8]. The mean IL-10 level was significantly higher among HIV infected individuals $(\mathrm{p}<0.001)$ in comparison to HIV seronegative controls in our study. There was no significant difference in the IL-10 level between the asymptomatic and symptomatic groups or symptomatic and AIDS infected individuals. IL-10 level has been reported to be significantly higher in symptomatic than in asymptomatic individuals, indicating a shift to the Th2/Th0 cytokine profile [12]. Klen et al. [8], also noticed a progressive increase in the proportion of CD4+T-cells expressing IL-10 in HIV infected individuals with AIDS compared to uninfected healthy controls. This may be consistent with the increase in plasma IL-10 seen in our population seen by us and Ramalingam et al. [12].

Whereas the frequency of IL-4 expression was reduced among CD4+T-cells from patients with AIDS, the percentage of IL-10producing cells increased significantly $(P<0.01)$ during the course of infection, among CD4+T-cells obtained from patients with AIDS as reported by Klein et al. [8].

In our study, relation between CD4+T-cell with IL-10 and TLC were observed to be inversely related while IL-2, IFN- $\gamma$, IL- 4 with CD4+Tcell count were observed to be positively related among case group with respect to symptomatic HIV negative patients, however the relation was not significantly observed. The relation between CD4+T-cell and IL-10 shows the negative non-significant relations in case group with respect to asymptomatic HIV positive patients. Similarly, a non-significant negative correlation was observed by Ramalingam et al. [12], between IL-10 with CD4+T-cell counts among the HIV infected individuals [12]. However, a significant negative correlation was observed between IL-10 levels and CD4+T-cell counts in HIV infected patients with or without active antiretroviral therapy [9]. There are other reports of negative correlation between IL-10 and CD4+T-cell counts [12,17] 
In our study, relation between CD4+T-cell with IL- 2 and IFN- $\gamma$ shows positive significant relations while the relation between CD4+Tcell and IL-4 shows positive relations in case group with respect to asymptomatic HIV positive patients, however the relation was not significantly observed. Whereas, a significant negative correlation has been reported between plasma IFN- $\gamma$ level and CD4 absolute count [12]. Except for IL-2, all other cytokines (IL-4, IL-10 and IFN- $\gamma$ ) have been shown to exhibit a negative correlation with the CD4+T-cell counts in HIV infected individuals compared with HIV negative subjects [9]. Among the cytokines (IL-2, IL-4, IL-10 and IFN- $\gamma$ ) Soufian et al. [9], examined IFN- $\gamma$ levels showed the strongest negative correlation.

CD4+T-cell count had significant negative correlation with IL-2 concentration as reported by Kang et al. [18]. However, IFN- $\gamma$, IL-2, IL10, Th1 cytokines levels and Th2 cytokines levels all had strong positive correlations with the cytokine concentration [18]. IFN- $\gamma$ secretion had a strong and intense relationship with Th1 cytokine levels, which indicated that IFN- $\gamma$ might play an important role in Th1/Th2 balance [18]. As there's no significant correlation between CD4+T-cell count and Th1 and Th2 cytokine levels, Kang et al. [18], proposed the possible reason for increasing cytokine expression was HIV itself. It was the stimulation of the HIV protein on T cells that caused the high cytokine expressions, which needed further study to reveal the molecular mechanism of this effect.

No correlation was observed between IL-2 and IL-10 levels in our study. In patients with HAART, IL-2 and IL-10 levels were similar to the control group and no differences were detected respecting CD4+T-cells counts [15]. Findings of Orsilles et al. [15] showed that the modifications in IL-2 and IL-10 serum levels in HIV infected patients naive of antiretroviral treatment are associated with the progression of immunological damage. Furthermore, they show a dysbalance of type-1/type- 2 cytokines with an involvement of type- 2 cytokines in later stages of HIV infection. Cytokine dysregulation can be reversed by HAART in the context of immune restoration and viral suppression as reported by Orsilles et al. [15]. A moderate, but significant, negative correlation was observed between IL-10 levels and CD4+T-cells counts [15].

\section{Conclusions}

In our study a positive correlation was observed between CD4+Tcell counts and Type-1 Cytokines (IL-2 and IFN- $\gamma$ ) among the Case group, while a negative correlation was seen between IL-4 and CD4+T-cell count in asymptomatic HIV positive patients and we also found significantly lower CD4+T-cell count and Type-1 Cytokines (IL-2, IFN- $\gamma$ ) in Case group as compared to the asymptomatic HIV patients. This depression in the production of Type-1 Cytokines may be responsible for the lower CD4+T-cell counts in these patients. Type2 Cytokine levels on the other hand were significantly higher in case group in comparison to asymptomatic HIV patients. Decline in type-1 cytokines (IFN- $\gamma$, IL-2) and rise in type- 2 cytokines (IL-4, IL-10) was observed in patients with HIV infection in comparison to asymptomatic HIV patients suggesting a shift from Th1 to Th2 type cytokine response indicates the progression in AIDS.

\section{Funding}

This work was supported by the Indian Council of Medical Research (ICMR), Government of India, New Delhi-110029, India.

\section{Declaration of Interest}

The author(s) declared no conflicts of interest with respect to the authorship and/or publication of this article and/or with funding agency.

\section{References}

1. Pattanapanyasat $\mathrm{K}$, Thakar MR (2005) $\mathrm{CD} 4+\mathrm{T}$ cell count as a tool to monitor HIV progression \& anti-retroviral therapy. Indian J Med Res 121: 539-549.

2. Worsley CM, Suchard MS, Stevens WS, Rie AV, Murdoch DM (2010) Multianalyte profiling of ten cytokines in South African HIV-infected patients with Immune Reconstitution Inflammatory Syndrome (IRIS). AIDS Research and Therapy 7: 36

3. Salim SAK, Quarraisha AK, Eleanor G, Cheryl B (2007) Global epidemiology of HIV-AIDS. Infect Dis Clin North Am 21: 1-17.

4. Douglas SD, Durako S, Sullivan KE, Camarca M, Moscicki AB, et al. (2003) $\mathrm{TH} 1$ and $\mathrm{TH} 2$ cytokine mRNA and protein levels in Human Immunodeficiency Virus (HIV)-seropositive and HIV-seronegative youths. Clin Diagn Lab Immunol 10: 399-404.

5. Fauci SA, Lane HC (2011) Human Immunodeficiency Virus (HIV) disease: AIDS and related disorders. Harrison's principles of internal medicine. (18thedn)

6. Saout CL, Lane HC, Catalfamo M (2012) The role of cytokines in the pathogenesis and treatment of HIV infection. Cytokine Growth Factor Rev 23: 207-214.

7. Wu TC, Kurman RJ (1997) Analysis of cytokine profiles in patients with Human Papillomavirus-associated neoplasms. J Nati Cancer Inst 89: 185-187.

8. Klein SA, Dobmeyer JM, Dobmeyer TS, Pape M, Ottmann OG, et al. (1997) Demonstration of the Th1 to Th2 cytokine shift during the course of HIV1 infection using cytoplasmic cytokine detection on single cell level by flow cytometry. AIDS 11: 1111-1118.

9. Soufian S, Aghakhani A, Mohraz M, Banifazl M, Eslamifar A, et al. (2012) No evidence of the Th1 to Th2 cytokine shift during the course of HIV infection. Iranian Journal of Pathology $7: 80-85$

10. Nigro L, Cacopardo B, Preiser W, Braner J, Cinatl J, et al. (1999) In vitro production of type 1 and type 2 cytokines by peripheral blood mononuclear cells from subjects coinfected with human immunodeficiency virus and leishmania infantum. Am J Trop Med Hyg 60: 142-145.

11. Rübsamen-Waigmann H, Deres K, Hewlett G, Welker R (2003) Viral Infections and Treatment: HIV Infection. ( $1^{\text {st }}$ edn $)$, CRC Press.

12. Ramalingam S, Kannangai R, Vijayakumar TS, Mathai D, Abraham OC, et al (2005) Subtype \& cytokine profile of HIV infected individuals from south India. Indian J Med Res 121: 226-234.

13. lannello A, Boulassel MR, Samarani S, Debbeche O, Tremblay C, et al. (2010) Dynamics and consequences of IL-21 production in HIV-infected individuals: a longitudinal and cross-sectional study. J Immunol 184: 114-26.

14. Tudela EV, Singh MK, Lagman M, Ly J, Patel N, et al. (2014) Cytokine levels in plasma samples of individuals with HIV infection. Austin J Clin Immunol 1 : 1003.

15. Orsilles MA, Pieri E, Cooke P, Caula C (2006) IL-2 and IL-10 serum levels in HIV-1-infected patients with or without active antiretroviral therapy. APMIS 114 $55-60$.

16. Parris Kidd (2003) Th1/Th2 Balance: The hypothesis, its limitations, and implications for health and disease. Altern Med Rev 8: 223-246.

17. Salvaggio A, Balotta C, Galli M, Clerici M (1996) CD4 count in HIV infection is positively correlated to interferon-gamma and negatively correlated to interleukin-10 in vitro production. AIDS 10: 449-451.

18. Kang W, Li Y, Zhuang Y, Zhao K, Huang D, et al. (2012) Dynamic analysis of Th1/Th2 cytokine concentration during antiretroviral therapy of HIV-1/HCV coinfected Patients. BMC Infectious Diseases 12: 102. 